\title{
Corrigendum to "Impact of Pressure and Brine Salinity on Capillary Pressure-Water Saturation Relations in Geological $\mathrm{CO}_{2}$ Sequestration"
}

\author{
Jongwon Jung' and Jong Wan $\mathrm{Hu}^{2,3}$ \\ ${ }^{1}$ Department of Civil and Environmental Engineering, Louisiana State University, Baton Rouge, LA 70803, USA \\ ${ }^{2}$ Department of Civil and Environmental Engineering, Incheon National University, Incheon 406110, Republic of Korea \\ ${ }^{3}$ Incheon Disaster Prevention Research Center, Incheon National University, Incheon 406110, Republic of Korea \\ Correspondence should be addressed to Jongwon Jung; jjung@lsu.edu
}

Received 2 November 2016; Accepted 24 January 2017; Published 14 March 2017

Copyright (C) 2017 Jongwon Jung and Jong Wan Hu. This is an open access article distributed under the Creative Commons Attribution License, which permits unrestricted use, distribution, and reproduction in any medium, provided the original work is properly cited.

In the article titled "Impact of Pressure and Brine Salinity on Capillary Pressure-Water Saturation Relations in Geological $\mathrm{CO}_{2}$ Sequestration" [1], reference [26] incorrectly cited the whole book. It should be corrected to cite chapter 1 only [2].

\section{References}

[1] J. Jung and J. W. Hu, "Impact of pressure and brine salinity on capillary pressure-water saturation relations in geological $\mathrm{CO}_{2}$ sequestration," Advances in Condensed Matter Physics, vol. 2016, Article ID 5603739, 11 pages, 2016.

[2] D. Broseta, "Assessing seal rock integrity for $\mathrm{CO}_{2}$ geological storage purposes," in Geomechanics in $\mathrm{CO}_{2}$ Storage Facilities, G. Pijaudier-Cabot and J.-M. Pereira, Eds., chapter 1, John Wiley \& Sons, New York, NY, USA, 2013. 

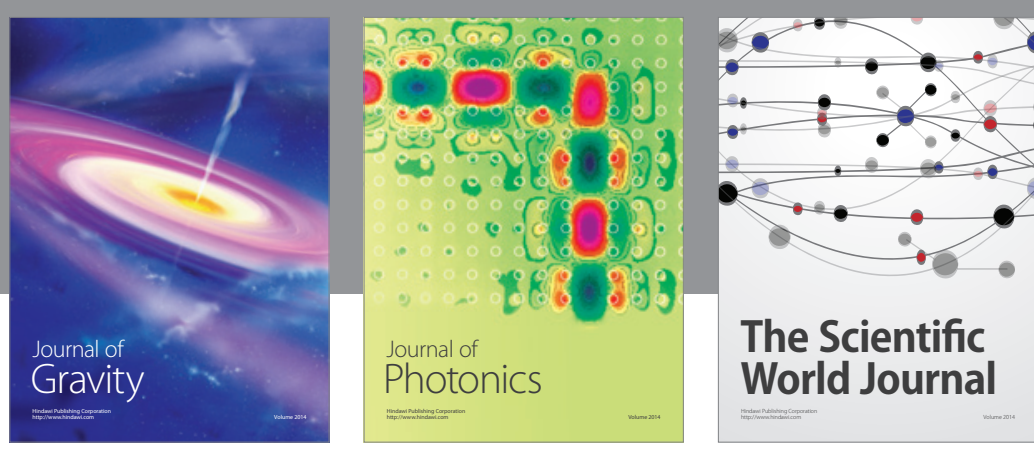

The Scientific World Journal
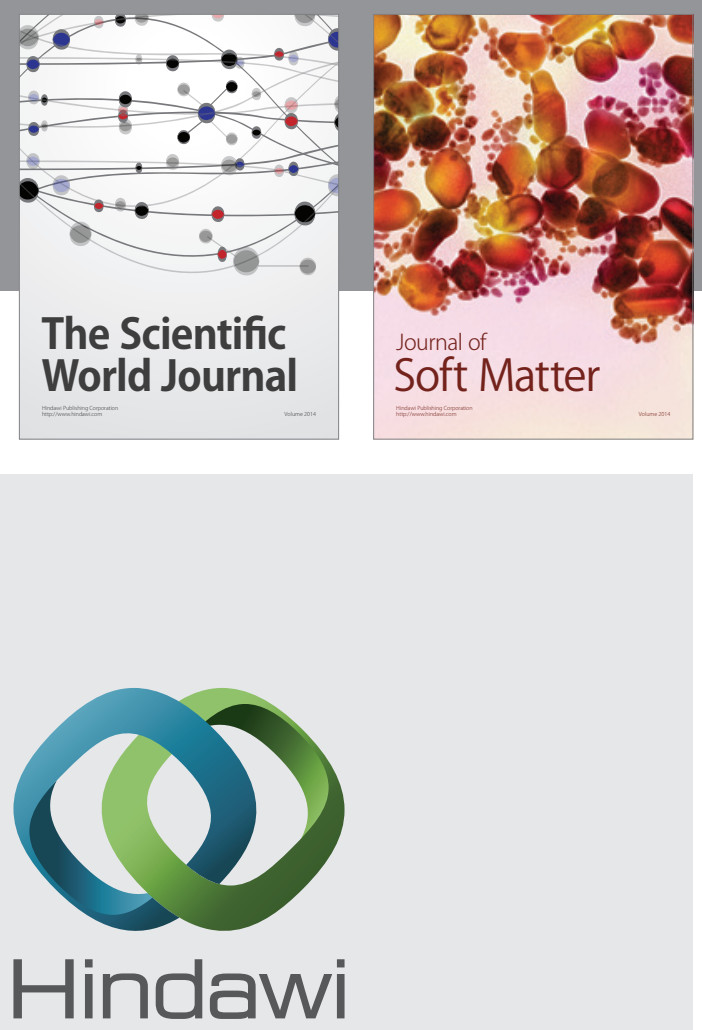

Submit your manuscripts at

https://www.hindawi.com
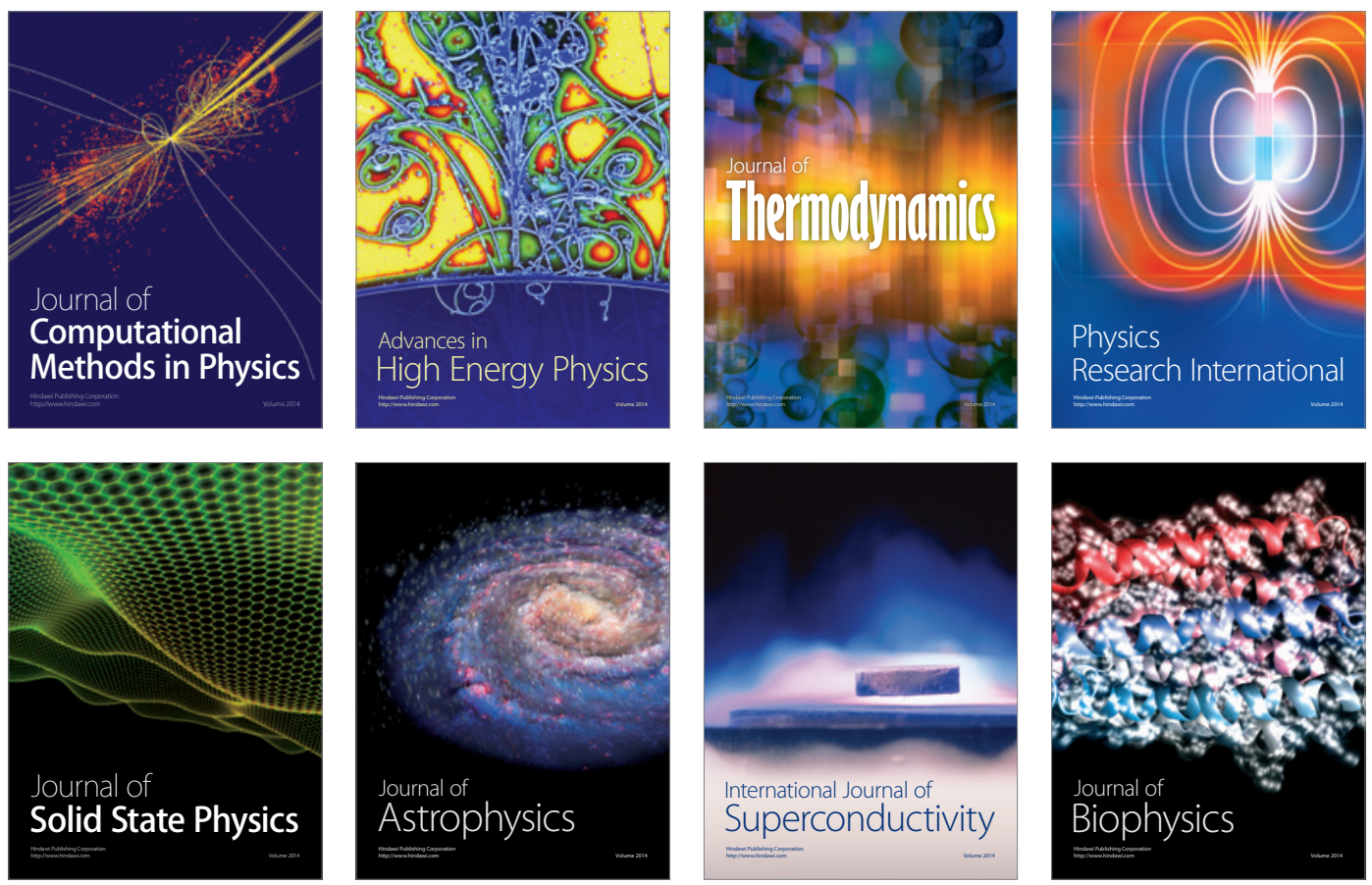
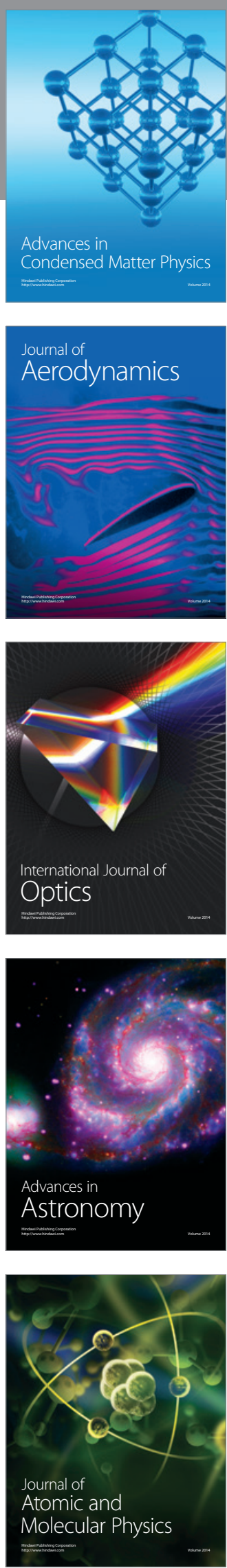